\title{
Use of portfolios to correct alternative conceptions and enhance learning
}

\author{
Takawira Kazembe ${ }^{1}$ \\ University of Zimbabw, P.O.Box MP167, Mount Pleasant Zimbabwe, Harare Zimbabwe
}

\begin{abstract}
Forty first-year primary school student teachers at a Teacher Training College in Masvingo Province, Zimbabwe, participated in an action research study, employing the science student portfolio, during February to July, 2008. They used the portfolio to record their prior knowledge about the lesson topic, new information learnt during the lesson, and how the new information related to their prior knowledge. Comments on lessons, monthly tests and assignment scores, reflections and a page-long conclusion were also recorded in the portfolio. The monthly test scores improved as the study progressed. Interviews revealed that alternative conceptions emanated from teachers, peers, textbooks, and the failure of students to understand teachers' explanations. Students' and administration's comments revealed stakeholders' satisfaction with the portfolio's effectiveness.
\end{abstract}

Key words: Alternative conceptions; action research; concept change; constructivist theory; portfolio.

\section{Introduction}

Students get into lessons already having intuitive ideas based on everyday experiences with the natural world, or the media or conversations. Some of these preexisting conceptions about scientific phenomena sometimes differ from those held by the general scientific community (Nakhleh 1992). Students integrate instruction with their existing ideas to generate new learning. Thus new learning is a synthetic result of students' existing knowledge and newly acquired knowledge (Meyer 2007). If the prior ideas are not congruent with scientific thinking, they may cause students to fail to construct concepts which are congruent with what scientists believe. Concepts which are not congruent with what scientists believe are called alternative conceptions (Nakhleh 1992; Novak 2000).

Alternative conceptions may hinder meaningful learning (Novak 2000; O" zmen 2004) because they form a faulty base upon which new knowledge will be built. Learning science is a cumulative process where new information is added to what students already have, constructing the knowledge basing on what they already know. Prior knowledge is the most important single factor influencing learning (Ausubel1963). What students do with information which is presented to them depends largely on what they already think and believe. According to constructivist theory of learning, each individual learner actively and uniquely constructs knowledge, interpreting new

\footnotetext{
${ }^{1}$ Correspondin author: Fax: 26304333407 E-mail: kazembetc@yahoo.co.uk
}

ISSN: 1306-3049, (C2010 
information in terms of existing cognitive structures. Teachers need recognize that only the learner can choose to learn meaningfully and to consciously and deliberately reconstruct his/her cognitive framework, and that learners will not be able to build new knowledge upon faulty prior knowledge. They, thus, must help students correct alternative conceptions and assist meaningful learning (Ausubel, Novak and Hanesian 1978; Taber and Watts 1997; Novak 2000; O“ zmen 2004). The ability of teachers to recognize and work with student-held ideas and conceptions is a key component of any effective educational strategy (Horton, et. al. 2004). It may be difficult for students to accept new information that contradicts what they think they already know because the new information seems wrong. The students may accept the new information and revise their prior knowledge/conception or they may accept the new information and memorize it so as to earn reward (Mulford and Robinson (2002). Thus, alternative conceptions may be present before any teaching has taken place and may also still be found after instruction (Taber and Watts 1997).

Since alternative conceptions learnt at an early age may persist into adulthood if left unchallenged, it is important to assess students' understanding of the concepts of the topics being taught, both before and after the lesson (Committee on Undergraduate Science Education 1997). The teacher should facilitate students' conceptual change by giving the student time to identify and articulate their preconceptions; investigate the soundness and utility of their own ideas against those of others, including scientists; and, reflect on and reconcile differences in those ideas. Thus the learner will be an active participant in the learning context rather than a vessel to be filled (O'zmen 2004). The teacher needs to be aware of students' ideas, expectations, and explanations prior to instruction; facilitate the exchange of views and challenges students to compare ideas; and provide opportunities for students to use scientific conceptions in familiar settings. True learning happens when the student is actively engaged at a deeper, intellectual level where "breakthrough learning" takes place. This happens at that magical moment of transformation where what seemed to be a confusing concept or unsolvable problem becomes obvious and much easier to understand (Johnson 2004).

Similarly, students base their alternative conceptions on their prior knowledge. They form the alternative conceptions by applying their prior knowledge to the situation to make sense out of it through the misunderstanding of experiences in school or incorrect information from literature or educators or peers. The key to changing the alternative conception is the discovery of concrete and unquestionable evidence experienced by the individual. This discovery must be made because existing alternative conceptions must be extinguished before new science concepts can be accommodated. Thus the key to correcting students' alternative conceptions is to find out and use what they already know. The challenge to teachers is to ensure that they do not leave intact students' alternative conceptions (O'zmen 2004).

Factors that have been identified to be responsible for development of alternative conceptions in school settings are poor method of instruction, improper exposure to laboratory and other learning activities, lack of organizational skills and inadequate exposure to problem-solving procedures (Adesoji and Babatunde 2008). Many alternative conceptions may be generated by students as they grapple with information and models presented in school which they are unable to imagine or understand. 
Many studies reveal that some teachers also hold alternative conceptions many of which are similar to those held by their students (Kruger \& Summers, 1988). It has also been demonstrated that teachers' thinking affects their behaviour and the ways they teach, limiting the kinds of science activities that students do, and their alternative conceptions even influence students' understanding of chemistry related concepts (Costa 1997; De Jong, Acampo, \& Verdonk 1995; McRobbie \& Tobin 1995).

This project seeks to identify alternative conceptions held by primary school student teachers, devise strategies to clear them, and establish the efficacy of the chosen strategy and its overall impact on the learning process. Different methods of instruction have been implemented in Chemistry classrooms. Abraham et al. (1992) reported that students exposed to discussion had higher test scores than those in the lecture or reading groups. The problems of alternative conceptions cannot be solved by providing students with the correct information. The students, themselves, must correct the problem. Hence, the practice of uncovering alternative conceptions offers a valuable tool which the teacher can use to help learners recognize errors and develop better understanding of the subject (Modell, et. al. 2005).

Several attributes separate action research from other types of research. It turns all the people involved into researchers. People learn best, and more willingly apply what they have learned, when they do it themselves. Action research takes place in real-world situations, and aims to solve real problems. The initiating researcher, unlike in other disciplines, makes no attempt to remain objective, but openly acknowledges his/her bias to the other participants (O'Brien, 1998). Action research is used in real situations, rather than in contrived, experimental studies, since its primary focus is on solving real problems. It is the method of choice when circumstances require flexibility, the involvement of the people in the research, or change must take place quickly or holistically (Winter 1989).

Students need to develop their own concepts, see how to link new concepts with their existing concepts, and develop their own strategies for higher level activities such as problem-solving (Coll 2008). The science student portfolio provides a strategy that fits into an action research to correct alternative conceptions. It is a model of instruction based on strategies that emphasize engaged learning in which students create meaning from their own experiences. It is a tool applicable across all subject areas. A portfolio is a purposeful collection of student work that tells a story of a student's efforts and achievements. It includes student participation in the selection of portfolio content, criteria for selection, for judging merit, and evidence of student self-reflection (Arter 1990). It facilitates development of skills and knowledge needed to construct understanding of science, technology and the world (Haury \& Rillero 1994). A true student portfolio must be student-owned, with content that reflects what the student knows, cares about, and provides an opportunity and structure for students to document and describe academic knowledge and reflect on what, how, and why they learn (Moseley 2000). When students become partners in the learning process, they gain sense of themselves as readers, writers, researchers, and thinkers. As they reflect on the different aspects of their learning, they develop tools to become more effective learners (Mifflin 1997). 
The benefits of portfolio use include greater involvement of students as they take more responsibility for maintaining and evaluating their own work. Students also benefit from authentic learning activities in a project orientation. This active participation by students is reflective of values held in science as a discipline. Portfolios document learning as a developmental process extending over time with a variety of tasks and opportunities for self-correction. The tasks assessed in portfolios use are representative of the tasks engaged in by scientists (Arter 1990).

The purpose and methods of assessment are broadened by the interactions teachers have with individual students to monitor meaningful learning and to guide instructional activities and decision making to help the students develop depth of knowledge in principled ways (Gitomer and Duschl 1995). Thus the science student portfolio gives the student opportunity to plan his/her learning, reflect on the activities expected of him/her to succeed, decide on what to do to succeed, including reading material, who to ask. The student may ask other teachers, peers, acquaintances, or any other knowledgeable people. Use of student portfolio is a strategy which should fit in well with the intended correction of alternative conceptions in an action research setting.

\subsection{Research questions}

- What alternative conceptions do students have?

- Will the portfolio offer the student opportunity for self-directed learning, self-reflection, responsibility for own-learning including goal-setting whilst correcting alternative conceptions?

- How will students and other stakeholders react towards the use of the portfolio?

\section{Methodology}

The research paradigm used in this study is a constructivist perspective which assumes that knowledge is not acquired passively (Yager 1991). Constructivist teachers of science promote group learning where two or three students discuss approaches to a given problem with little or no interference from the teacher. There are many paradigms in the field of educational research, some approaches being more useful than others (Magagula 2004).

The qualitative methodology is useful for understanding how students learn using the constructivist perspective as it draws from the theoretical framework of phenomenology (Macmillan \& Schumacher 1993). The participant qualitative researcher, being part of what is being studied, will have direct understanding of the circumstances of the object of study because he/she will be in the latter's shoes. Thus, the researcher gets close to the respondents, situations and phenomena under study.

This research was designed to be a case study to permit an intensive, holistic description and analysis of the implementation of an innovative teaching strategy. A case study is a flexible and adaptable in-depth study of instances of a phenomenon in its natural context and from participants involved in the phenomenon. It allows for prolonged engagement with participants (Bogdan \& Biklen 1992; Macmillan \& Schumacher 1993; Borg \& Gall 1996). The use of multiple methods of data collection 
about a phenomenon enhances validity of findings through triangulation (Borg \& Gall, 1996). The findings of a case study can be transferable to other situations which are similar, depending on the judgement of the reader (Lincoln \& Guba 1985).

This case study employed action research where the researcher guided students construct portfolios which they used to record the events that took place during the teaching and learning process. They recorded topic and test reflections, projects, summary of assessment and portfolio conclusions. The headmaster of the school and the Head of Department were invited to comment on the activities of the participants. The researcher used the information from the portfolios to fine-tune his teaching approach.

\subsection{Gaining field entry}

The researcher got an introductory letter from the University of Zimbabwe which assured the principal that all the information was to be held in strict confidence. Permission was also sought from the Provincial Education Director, Masvingo, Zimbabwe, as suggested by Best and Kahn (1993). The consent of students was sought immediately after the principal had given the go ahead.

The researcher expended considerable effort in introducing the new approach to teaching and learning chemistry, as the students had to fully understand why they were being asked to embark on this time consuming exercise. Within two weeks of starting, students had grown a liking for the procedures and were proud to own a portfolio, which they were seen to possessively talk about on the school grounds, especially during break times.

The administration became very supportive of this new approach after the researcher explained the intricacies to them.

\subsection{Instruments}

The student portfolio was used to expose alternative conceptions; to record how new information was received by the students; to record test results, assessment results and products of reflections on the results, and finally, to record the conclusion of the project at the end of the term.

Interviews served to capture what students might not have wanted to commit to writing or what they might not have thought of when they entered information in the portfolios. Probing by the researcher unearthed information which ended up being valuable to the research.

Observations were used to capture what and how students did as they tried to get information to solve their problems. This was important as it gave an opportunity to discover what difficulties students had with sources of information such as asking the right questions in a manner that would be understood by the informant, including the computer.

\subsection{Sampling}

The whole first year chemistry class consisting of 40 primary school student teachers (15 girls and 25 boys) was used for this study because taking a sample would 
have created an extra class to teach and the job might have been insurmountable. The students enroll to train to teach after graduation from form four.

The study topics were taken as they are normally taught at the college at the beginning of the year. Using the portfolio teaching a large class of forty is timeconsuming and formidable for one teacher. According to Pheeney (1998), portfolios can become massive unmanageable, unfocused and cluttered, as a result, they often get abandoned by the teachers and students. For large classes, some teachers end up having endless supplies of checklists, scoring rubrics and reflection sheets never to be seen or heard of again.

Having a large portfolio class was, however, considered less cumbersome than having a portfolio class and a conventional class at the same time. The college has three science laboratories which are reasonably satisfactorily equipped for its purposes.

\subsection{Data collection}

Data collection took place between February and July 2008, using the portfolio, participant observation, and open-ended interviews. The procedure to be followed in the study was carefully explained to the students who were then given a course outline which they would follow and record in their portfolios (1) what they already knew about the topics, indicating where they got the information from, and (2) what they expected to learn in the topics. They had to hand over the portfolios to the researcher at least two days before the lesson so that the researcher would peruse the portfolios and look for misconceptions and hand back the portfolios before the lesson. The researcher prepared the lesson with revealed alternative conceptions in the portfolios in mind.

The students recorded what they had learnt during the lesson, indicating areas they had difficulties with, and commend on the relationship between their prior knowledge and what they got in the lesson. Multiple questions on the studied topics were given on a monthly basis. The students were asked to reflect on their test scores and indicate in their portfolios where they had gone wrong and suggest corrective measures.

This was repeated covering the topics every month, and an assignment covering all the topics studied was given towards the end of the study period. The students were asked to reflect on their assignment marks and indicate how they would work towards improving their scores. Finally, students were asked to reflect on their test scores, draw conclusions on their successes and failures, after which they would write a one page concluding statement.

\section{Results}

\section{Alternative conceptions about atomic structure}

The negative charge of the electrons are in the nucleus neutralize the positive charge of the protons $(30 \%)$.

Electrons circulate the nucleus in orbits $(60 \%)$.

Electrons are particles that move around the nucleus of an atom (50\%).

$\mathrm{An}$ atom is the smallest particle of a substance that cannot be broken down further $(70 \%)$.

Nucleus is not attracted by electrons $(20 \%)$. 
Nucleus attracts electrons more than electrons attract electrons. (25\%).

Each proton in the nucleus attracts one electron (33\%).

Electrons move around the nucleus in orbits, just like planets do (35\%).

A molecule is the smallest element in an atom (15\%).

Some regarded elements as particles which make up compounds (50\%).

\section{Alternative conceptions about bonding}

1. Covalent bonding is when an element loses an electron to become stable (30\%).

2. Ionic bonding is when an element shares electrons chemically (15\%).

3 . The ionic bond has high melting point and high boiling point whereas covalent bond has low boiling point $(25 \%)$.

4. In covalent bond elements lose electrons and in ionic bonds elements share electrons. $(25 \%)$.

5. Ionic bonding is formed when two non-metals share electrons and of the two, one does not change back to the original $(15 \%)$.

6. Metallic bonding is weak bonding (10\%).

7. Intramolecular covalent bonding is weak bonding ( $45 \%)$.

8 . Ionic bonding is weak bonding $(25 \%)$.

9. Continuous metallic or ionic lattices are molecular in nature $(35 \%)$.

10. The bonding in metals and ionic compounds involves intermolecular bonding (45\%).

11. The ionic radius of sodium ion is bigger than that of chloride ion $(25 \%)$.

12. Metal to nonmetal bonding in alloys is electrostatic bonding (15\%).

13. Molecular iodine contains iodine minus ions, hence solid iodine shines like metal. $(25 \%)$.

14. The charged species in metallic lattices are nuclei rather than ions $(25 \%)$

15. Chemical substances react to form compounds (35\%).

16. Atoms share electrons because they want to form stable compounds $(33 \%)$.

17. Atoms lose or gain electrons when they react because they want to achieve the stable octet of electrons in their valence shells $(55 \%)$.

18. Chemical substances react because of the number of electrons and protons in the element (35\%).

19. Bond breaking is exothermic and bond making is endothermic (40\%).

20 . Bonds glue atoms together (15\%).

21 . The chemical bond is a physical thing made of matter (45\%).

22. The strengths of covalent bonds and intermolecular forces are similar (40\%).

23. Bonds within "ionic molecules" are stronger than inter-molecular forces $(25 \%)$.

24. Electrons know which atom they came from (45\%).

25. Atoms are held together because they share electrons, so sharing electrons is like a force $(45 \%)$.

\section{Alternative conceptions about solids}

1. Heating does not cause particles of a substance to expand (35\%).

2. A molecule is the smallest element in an atom (10\%).

3. Elements are particles which make up compounds (15).

4. Compound is a mixture of molecules $(20 \%)$. 
5. The shapes of molecule are due only to repulsion between non-bonding electron pairs $(30 \%)$.

6. The shapes of molecules are due only to repulsion between bonding electrons.(35\%).

7. Electron pars are equally shared in all covalent bonds (50\%).

8. Van der Waals forces are not really chemical bonds, but just forces operating in molecules $(10 \%)$.

9. Molecules expand when heated (35\%).

10. Molecules are glued together. Forces of attraction hold molecules together, not glue $(25 \%)$.

11. Bonds store energy, breaking chemical bonds releases energy, and bond making requires energy $(80 \%)$.

12. Ionic molecules such as $\mathrm{Na}+$ and $\mathrm{Cl}$ - ion pairs $(30 \%)$.

13. The chemical bond is a physical thing made of matter $(20 \%)$.

14. Ionic compounds form neutral molecules, such as $\mathrm{Na}^{+} \mathrm{Cl}^{-}$molecules, in water (40\%).

15. Bonds within "ionic molecules" are stronger than inter-molecular forces (35\%).

16. Electrons know which atom they came from (80\%).

17. The strengths of covalent bonds and intermolecular forces are similar (10\%).

18. Freezing and boiling are examples of chemical reactions $(45 \%)$.

\section{Alternative conceptions about matter and particles}

1. If some of the gas is sucked out of a container the remainder does not fill the container $(20 \%)$.

2. Matter is lost in changing from solid to liquid and liquid to gas and there are material differences between solid, liquid and gas particles (35\%).

3. The molecules of water in ice are hard and frozen and start moving when the ice melts as the particles dissolve (75\%).

4. Particles expand and contract as they are heated and cooled (35\%).

5. The bubbles observed when water boils consist of water surrounding heat, oxygen, hydrogen or steam $(20 \%)$.

\section{Alternative conceptions about chemical equilibria}

- Freezing and boiling are examples of chemical reactions (15\%).

- Physical changes are reversible but chemical changes are not $(25 \%)$.

- Reactions that proceed rapidly will be more complete than those that proceed more slowly (35\%)

- Chemical reactions will continue until all the reactants are used up (15\%).

- Chemical equilibria are static (15\%).

- Energy is used up in chemical reactions (35\%).

- Non polar substances do not mix with water because water molecules and non polar molecules repel each other $(30 \%)$.

- Oil is not miscible with water because water and oil molecules repel each other $(40 \%)$.

- Energy is released when chemical bonds form (35\%).

- Energy is conserved in chemical reactions (30\%).

- Water molecules in steam are larger than those in ice (15\%).

- Vapour particles are held by bonds and other forces (25\%). 
- Uniform distribution of gas particles is due to repulsive forces (35\%).

- Decrease in volume of a gas on cooling is due to increased attractive forces (45\%).

\subsection{Interviews}

Interviews revealed that most of the alternative conceptions resulted from students' failure to understand teachers' explanations in preceding classes and not necessarily because of their teachers' alternative conceptions. The teachers' shortcomings cannot, however be ruled out since some teachers are known to exhibit such problems.

\subsection{Observations}

Observations complemented interviews and gave the researcher real time evidence of the value of the portfolio as it gave insights into attitudes, feelings, and confidence of the participants. Participants were observed exhibiting constructive attitudes towards the portfolios, being at ease and methodically working at their problems, seeking information from their peers, teachers, the library, and the researcher.

Portfolio records, interviews, test scores and assignment scores could not have given this type of evidence as it exposes some traits individuals would not feel safe to talk about and would rather prefer to hide them. The researcher, however, captured the traits and included them in his arsenal for corrective action. The traits included copying neighbours work, walking about as if aimlessly, failure to concentrate on whatever the student was doing, and disturbing neighbours. The culprits were notified of the futility and dangers of their actions. The most often observed culprits happened to be the ones with the largest numbers of alternative conceptions. However, such observations contributed towards the correction of most of their faulty conceptions. These students probably had that many alternative conceptions because they do not pay attention to teachers during lessons and do not concentrate on school work. Their minds wander as they are talked to and they do not concentrate enough to follow instructions. Conventional instruction is not likely to do much to help such students correct their faulty conceptual structures.

\section{Discussion}

In general, the alternative conceptions could not be traced to culture-based enacted worldviews. They appeared to be related to previous lessons, hence traceable to teachers, textbooks and failure of students to comprehend.

Teachers have been reported to exhibit a wide range of alternative conceptions similar to those of their students. Carlsen (1993) observed that teachers who are poorly topic knowledgeable rely on low-level questions and generally give their students less opportunities to speak. Students taught by such teachers often do not have opportunity to ask for explanation on what they fail to grasp, hence rely on building their knowledge bases without proper supervision and thus inherit the teachers' alternative conceptions. Thus, alternative conceptions arise, not only from students' contacts with the physical and social world and from textbooks, but also as a result of interaction with teachers (Strauss, 1981; Cho, Kahle, \& Nordland 1985; Gilbert \& Zylberstajn 1985). 
The possibility that some of the alternative conceptions are results of teacher action is alluded to in the reply given by one of the teachers of these students when asked to give some of the alternative conceptions the students might have. The teacher simply said "I am not aware of any alternative conceptions the students have in chemistry". The teacher in question was a university trained science teacher. That he was not aware of any alternative conceptions probably implies that he did not bother about students' alternative conceptions.

Since teachers' knowledge of the subject matter and their conceptions about the phenomena they teach can enhance or limit students' learning, student teacher curricula should include management of students' alternative conceptions. Constructivist approaches to teaching and learning acknowledge the role that prior conceptions held by learners play in the learning process. Science educators should accordingly devote research efforts to elicit and build on prospective teachers' conceptions if they want to get rid of alternative conceptions during pre-service or in-science training.

Some of the ways some textbooks explain concepts, e.g. "the availability of energy from energy-rich ATP bonds" likely lead to alternative conceptions. Students who study biology and chemistry would not be blamed for taking such ideas from biology to chemistry classes. However, some student views of more common concepts are less easily understood and it is likely that they are influenced by other factors such as cultural background. However, the alternative conceptions observed in this study do not appear to emanate from cultural influences, as literature shows that they are not peculiar to this part of the globe. Although some student alternative conceptions may arise as a result of the learning process itself some studies suggested that factors other than the school environment and the teaching processes used may also influential in student learning (Coll 2008). Interviews with students during this project revealed that some of the alternative conceptions are a result of students' failure to understand teachers' explanations in class.

Alternative conceptions are not limited to school children. Comments on this present report by some chemistry graduates revealed that even some recent university chemistry graduates still think of atomic structure in terms of the Bohr model. Some gave answers that are difficult to attribute to any recognizable model of atomic structure, indicating a lack of understanding of a fundamental and comparatively simple scientific concept. Attempts to unravel the source of this alternative conception could not pin the problem even to the graduates' undergraduate lecture notes. The alternative conceptions had to be blamed on the textbooks which failed to express the inappropriateness of the theory to today's thinking.

Bucat (1984) observed that chemistry textbooks give the particle theories emanating from Dalton's atomic theory and the molecular kinetic theory as if they are unrelated. They rarely appear together explaining their relationship to aid understanding and prevent development of alternative conceptions. Some alternative conceptions may be learned from textbooks in other subjects. For example, "Breaking chemical bonds releases energy." The concept of bonds storing energy is widely used even by biologists (O’zmen 2004). 
The traditional teaching approach does not permit time or space to reveal students' alternative conceptions to the teacher before lessons. Assumptions are made before each lesson that the students learned as the teachers intended. Little time is given to discovering children's prior ideas and to addressing them. As a result, students exhibit very muddled thinking as they attempt to assimilate new scientific views in the lesson. Teachers should allow children's ideas to develop by revisiting the topic and by providing opportunities for alternative conceptions to be expressed in a "safe" environment (Kind 2004). The student portfolio allows students to show teachers what they already know and, thus, gives the teachers opportunity to reflect on the alternative conceptions and address them. If they emanate from community science which the teacher might not be familiar with, the teacher may create opportunities to study the community science and address the problems appropriately. Students are also given opportunity to consolidate the new information as they reflect on their ideas after lessons.

In this study, the teacher did not set aside time to correct the alternative conceptions, but planned the lessons with the alternative conceptions in mind and addressed each of them as part of the normal lesson. He invited students to reflect on what they had written in their portfolios before the lesson, compare the information with what they had learnt in the lesson and resolve on what they were going to do to make sure that their ideas were corrected. Students wrote their resolutions in the portfolios and acted upon them.

Their resolutions included discussing their problems with peers, consulting with their teacher(s), researching in the library, and holding group discussions. Success of their resolutions and activities was tested in the scheduled monthly tests. Students were, again, invited to reflect on their performance in the tests and make resolutions on how they were going to correct and improve their performance.

The portfolio was employed as a vehicle for conceptual change based on constructivism. For its success, the researcher helped create the necessary conditions: dissatisfaction with alternative concepts, intelligibility of new information, plausibility and fruitfulness of conceptual change (Posner et al. 1982). The reflections on consultations with peers and peer group discussions facilitated conceptual change and helped students to be aware of their alternative conceptions and provide chance to overcome them (Huddle \& Pillay 1996; Canpolat et al. 2006). Students were, thus, encouraged to play with ideas as this would likely increase their interest in scientific thinking. This was in line with Lewis and Linn (1994) who argued for a curriculum that includes everyday knowledge, to encourage integration of knowledge, to engage students in building on their intuitive conceptions, and to make scientific knowledge easier to remember.

The test performance improved as students got more familiar with the use of portfolios. The average score rose from about $50 \%$ at the beginning to about $70 \%$ by the end of the sproject's five months later. The final test ranged $70-90 \%$, and the alternative conceptions appeared to have disappeared. The students as well as the administration eulogised the use of portfolios.

The use of portfolio in this study did not appear to affect the amount of content covered as is the usual complaint against teaching by a constructivist approach. The 
content covered was comparable to what has been covered in the same period over the years at this school. The apparent disappearance of alternative conceptions was also contrary to the usual cry about the "remarkable tenacity of many student alternative conceptions" as observed by Coll (2008).

The apparent success is probably due to the enthusiasm with which students accepted the portfolio which motivated them to work hard and keep up with the pace at which the teacher attempted to cover the syllabus. The students were so excited about the portfolio that the researcher occasionally feared that the exercise might succeed at the expense of other subjects.

Alternative conceptions arise not only from students' contacts with the physical and social world and from textbooks (Cho et al. 1985), but also as a result of interaction with teachers (Gilbert and Zylberstajn, 1985). Teachers should discuss abstract concepts in their classrooms in order to eliminate students' alternative conceptions.

When the teachers were less knowledgeable, they were more likely to rely upon low-level questions and to give their students less opportunities to speak (Valanides 2000). According to Bergquist and Heikkinen (1990), it is critical to provide students with opportunity to verbalize their ideas to promote concept building and remediate alternative conceptions. Only then will deep-seated misunderstandings be identified, diagnosed, and addressed. The use of the students' science portfolio addresses the problem according to these suggestions and the success might be related to such attributes.

Although incorrect, imprecise, or incomplete teaching may play an important role, according to Tsaparlis (1997), there must be a more fundamental cause that results in one or more of the following:

i) the inability of most or many students to employ formal operations,

ii) the lack of the proper knowledge corpus which is a prerequisite for meaningful learning,

iii) the absence of the relevant concepts from long term memory.

The portfolio allows students time to construct concepts for themselves and develop ability for formal operations. The portfolio allows knowledgeable people of students' choice to facilitate meaningful change. The activities in portfolio use vindicate Driver and Oldham suggestion (1986) that students be allowed time to construct concepts for themselves. Thus, use of the portfolio augurs well for concept change leading to correction of alternative conceptions. In addition, researchers indicate that students' difficulties and alternative conceptions in learning science concepts are due in part to the teachers' lack of knowledge as regards students' prior understanding and knowledge of concepts under study (Krishnan and Howe1994).

The identification of possible sources of alternative conceptions is important because the instructional strategies which ultimately might prove effective in combating alternative conceptions might differ according to the type or source of the alternative conception. One of the most fruitful outcomes of the studies on children's alternative conceptions is to alert teachers to students' difficulties in conceptualizing science knowledge and hence suggest more effective strategies for improving classroom instruction. Before teaching a concept, teachers should be able to check the literature to 
find out what is known about alternative conceptions that students may bring to class and which teaching methods are the best in correcting these alternative conceptions. Such an approach would provide to teachers a chance to design better learning environments that help to develop concepts scientifically.

The constructivist literature emphasizes that the teacher always has to teach from where the students are rather than where the teacher would like them to be, or where the curriculum suggests they should be (Taber, 2001). The way the portfolio was used in this study was in agreement with this observation. Students' ideas were made explicit at the start of the teaching sequence (Driver and Oldham 1986). Students gave their portfolios to the researcher so that they could be perused as part of lesson planning and it paid dividends. According to constructivist view of learning, meaningful learning occurs when the learners actively construct their own knowledge by using existing knowledge to make sense of newly gained experiences. Taber (2000) has stated that the first step in a constructivist learning approach is to make the teacher and student aware of the learner's current ideas. Teaching can then be planned that challenges alternative conceptions, and provide students with the opportunities and rationale for conceptual restructuring.

Thus, the portfolio played an important role in concept change. The researcher helped students eliminate their alternative conceptions by providing an adequate knowledge base and clear understanding of concepts. Because alternative conceptions affect subsequent learning negatively (Bodner 1986), the correction or remediation of students' alternative conceptions is as important as identification of them.

In his approach to teaching in this study, the researcher attempted to satisfy the following conditions reported by Posner et al. (1982) and by Chambers and Andre (1997):

(i) students must become dissatisfied with their existing conceptions; students must have experiences which lead them to lose faith in the ability

of their current conceptions to solve problems,

(ii) the new conceptions must be intelligible; the student must be able to understand sufficiently how experiences can be structured by the new concept, (iii) the new conception must appear plausible; any new concept adopted must at least appear to have the ability to solve the problems generated by its predecessors,

(iv) the new conception must be fruitful; it should have the capacity to open up new areas of inquiry.

Use of the portfolio promoted self-directed learning, motivated students and ultimately facilitated learning as suggested by Lumina (2005). Students' topic reflections suggested ways of dealing with identified problems from the topics and tests. One of the students, Monna said, "The statement about electronic orbits was different from what we were taught last year. I shall research in the library". Torayi said, "Assignment discussions in my group improved my attitude towards learning". Tonderayi had problems appreciating the lack of polarity in some bonds said: "I am determined to research in the library and practice with similar compounds such as $\mathrm{CO}_{2}$ ".

Panganayi said, "Learning through reflections, projects, and tests made me appreciate scientific processes at home". Sarayi said: "I need to change my attitude 
towards tests and be confident before tests in chemistry." Doro wrote: "I shall try and improve my graph through revision and team discussions." These statements vindicate Lumina's suggestions (2005) that portfolio can assist students reflect on their learning in a manner that can enhance their learning; and Moseley (2000) who suggested that the ability to think about what one does and why, while assessing and reflecting one's past actions, current situations, and intended outcomes, is vital to intelligent practice that is more reflective than routine.

Mifflin (1997) observed that students need to think about what they do well and in which areas they still need help. Pfidzayi agreed and wrote: "I am getting help from the teacher and my classmates so as to be able to understand electronic configuration."

The portfolio made students responsible for their own success and feel empowered about their own learning (Pheeney 1998). Students suggested solutions to their identified problems. For example, Jinja and Cella resolved to study seriously and swore to work hard. Cella wrote: "I shall do anything to pass chemistry." These sentiments are compatible with Moseley's statement (2000) that a true portfolio must be student owned, with the actual content reflecting what each student knows, cares about, and is able to do and not able to do.

Students developed tools to become more effective learners and set new goals for themselves as they reflected on what and how they had learnt, (Mifflin 1997). After a self-reflection exercise, Ellah said, "I am now working on the next topic, chemical bonding." After his test reflection, Giles said: "I want to study extra hard so that I have better achievement in the next test." Blessing said: "I want 'A' grades in the upcoming tests. I know I will meet my targets. I will continue reading and researching using my seniors and the library so that I beat my target of $90 \%$ ".

The College Principal commended: "This approach will yield high quality results in chemistry. It motivates students to learn and it appears that the involvement of all stakeholders in the implementation of the curriculum may improve the teaching and learning of chemistry.

\section{Conclusion}

The use of the portfolio as a teaching and learning tool led to dramatic results that satisfied all stakeholders. The portfolio is an effective tool although it is not widely used because it is time consuming. It has the potential to satisfy the need for effective concept change approaches that stimulate, excite, challenge, empower, and engage students. The portfolio may challenge science educators to change their teaching strategies and provide real world learning opportunities for students. It can empower students to develop a sense of ownership of their science learning, nurture students, foster a positive self-concept of learning, and involve students in self-reflection and in determining and setting individual goals.

\section{References}

Abell, S. K. \& Smith, D. C. (1994). What is science? Preservice elementary teachers' conceptions of the nature of science. International Journal of Science Education., 16, 475-487. 
Abraham, M.R., Grzybowski, E.B., Renner, L.W., and Marek, E.A. (1992). Understandings and misunderstandings of eighth graders of five chemistry concepts found in textbooks, Journal of Research in Science Teaching 29, 105-120.

Adesoji, F. A. and Babatunde, A. G., (2008). Investigating Gender Difficulties And Misconceptions In Inorganic Chemistry At The Senior Secondary Level, International Journal of African \& African American Studies, Vol. VII, No. 1, Jan 2008.

Arter, J., (1990), Reported in "Project to Advance Science Education", College of Education \& Health Professions, University of Arkansas. Retrieved 24 May 2009.

Ausubel, D. P., The Psychology of Meaningful Verbal Learning. New York: Grune and Stratton, 1963.

Ausubel, D. P., Novak, J. D. and Hanesian, H., (1978), Educational Psychology:A Cognitive View. New York: Holt, Rinehart and Winston, 1978. Reprinted 1986, New York: Werbel \& Peck.

Bergquist, W. and Heikkinen, H. (1990). Students' ideas regarding chemical equilibrium, Journal of Chemical Education, 67 (12) 1000-1003

Best, J. W. and Kahn, J. V. (1993), Research into Education. London: Allyn and Bacon, pp 183-241.

Bogdan, R. C. and Biklen, S. K. (1992). Qualitative Research for Education: An introduction to Theory and Methods. Boston. Allyn and Bacon, pp 29-149.

Borg, M. D., Borg, W. R. and Gall, J. P.(1996). Educational Research: An Introduction. U.S.A: Longman, pp 203-204.

Bordner, G.M., (1986). Constructivism: A theory of Knowledge, Journal of Chemical Education, 63, (10), 513-514.

Bucat, R. B. (ed.) (1984). The elements of chemistry: Volumes 1 and 2. Canberra: Australian Academy of Science.

Chambers, S. K. \& Andre, T. (1997). Gender, prior knowledge, interest, and experience in electricity and conceptual change text manipulations in learning about direct current. Journal of Research in Science Teaching, 34 (2), 107-123.

Cho, H., Kahle, J. B., and Nordland, F. H. (1985). An investigation of high school biology textbooks as sources of misconceptions and difficulties in genetics and some suggestions for teaching genetics. Science Education 69: 707-719.

Coll, R. K., (2008). (2008). Do We Expect Too Much? Reflection on Chemistry Content in Higher Education. A publication from the NZIC Chemical Education Special Interest Group, University of Waikato (e-mail: r.coll@waikato.ac.nz), Chemistry in New Zealand.

Committee on undergraduate studies. US (1997). Misconceptions as barriers in understanding science. In Science teaching reconsidered: A handbook (chap. 4). Retrieved January 22, 1004, from http://books.nap.edu/readingroom/books/str/4.html. 
Conpolat, N., Pinarbasi, T., Bayrakceken, S. \& Geken, O. (2006). The conceptual change approach to teaching chemical equilibrium, Research Science \& Tecknological Education, 24 (2), 217-235.

Costa, V. B. (1997). How teacher and students study "all that matters" in high school chemistry. Journal of Science Education, 19, 1005-1025.

De Jong, O., Acampo, J., \& Verdonk, A. (1995). Problems in teaching the topic of redox reactions: Actions and conceptions of chemistry teachers. Journal of Research in Science Teaching, 32, 1097-1110.

Driver, R., and Oldham,V. (1986). Aconstructivist approach to curriculum development in science. Studies in Science Education, 13: 105-122.

Gilbert, J. K., and Zylberstajn, A. (1985).Aconceptual framework for science education: The case study of force and movement. European Journal of Science Education 7: $107-120$.

Gitomer \& Duschl, (1995). Inquiry and the National Science Education Standards: A Guide for Teaching and Learning. (2000).Center for Science, Mathematics, and Engineering Education (CSMEE), page 122, Retrieved 23 May, 2009.

Haury, L. and Rillero, P., (2007), Perspectives of hands-on science teaching, (1994), http://www.nerel.org/schs/ares/issues/conent/entrareas/eric/eric-3html. Retrieved 16 November 2007

Horton, C., Worcester, MA 01602 with other members of the Modeling Instruction in High School Chemistry Action Research Teams at Arizona State University: June 2001, August 2002 and August 2004, Student Alternative Conceptions in Chemistry (Originally: Student Misconceptions and Preconceptions in Chemistry).

Huddle, P. A., and Pillay,A.E. (1996).Anin-depth study of misconceptions in stoichiometry and chemical equilibrium at a South African University. Journal of Research in Science Teaching 33: 65-77.

Johnson, B., (2004). Exclusive interview with Dr Benny Johnson, President \& CEO, Quantum Simulations, Inc., Published on Sunday, October 03, 2004 - 10:41 PM PST, Source: Distance-Educator.com, Retrieved 25 January, 2009.

Kind, Vanessa (2004). Beyond Appearances: Students' misconceptions about basic chemical ideas, 2nd Edition, School of Education, Durham University, UK. Selfpublished; available at $<$ http://www.chemsoc.org/pdf/LearnNet/rsc/miscon.pdf $>$ (Vanessa Kind as formerly Vanessa Barker.), Retrieved 16 May 2009. Krishnan, S. R., and Howe, A. C. (1994). The mole concept: Developing an instrument to assess conceptual understanding. Journal of Chemical Education 71(8): 653-658.

Kruger, C. \& Summers, M. (1988). Primary school teachers' understanding of science concepts. Journal of Education for Teaching, 14, 13-17.

Lewis, E. and Linn, M. (1994). "Heat, Energy and Temperature Concepts of Adolescents, Adults and Experts: Implications for Curriculum Development", Journal of Research on ScienceTeaching 31(6) 657-77. 
Lincoln, Y. S. and Guba, E. G., Naturalistic Inquiry. Newbury Park: Sage Publications, 1985, pp214-215.

Lumina, C., (2005). Giving greater students responsibility for their own learning: Portfolio assessment and peer marking as tools for promoting self-directed learning in second year law course. South African Journal of Higher Education, 19(3) 482496.

MacMillan, J. H., and Schumacher, S., (1993). Research in Education: A conceptual introduction. New York: Harper. Collins. College Publishers. p 376.

Magagula, C., (2001). The issue of paradigms in educational research: Keeping the debate alive. The Zimbabwe Journal of Educational Research, 8 (3) 233-254.

McRobbie, C. \& Tobin, K. (1995). Restraints to reform: the congruence of teacher and student actions in a chemistry classroom. Journal of Research in Science Teaching, 32, 373-385.

Meyer, H. (2007). Is it molecules? Again! A review of students' learning about particle theory. The Chemical Education Journal (CEJ), Vol. 9, No. 2 (Serial No. 17).

Mifflin, H._(1997). Students as active partners. Houghton Mifflin Company, 1997. http://www.eduplace.com/rgd/res/assess/partners.html. Retrieved 10 April 2008.

Modell, H., Michael, J., Wenderoth, M. P., (2005). Helping the Learner to Learn: The Role of Uncovering Misconceptions, National Association of Biology Teachers, BioOne online journals, The American Biology Teacher, 67(1):20-26. 2005. Retrieved 25 May, 2009.

Moseley, C., (2000). Standards Direct Pre-service Teacher Portfolios. Science and Children, 37 (5) 30-43.

Mulford, Douglas R., and Robinson, William R. (2002). An Inventory for Alternate Conceptions among First-Semester General Chemistry Students, Journal of Chemical Education. 79 (6), 739-744.

Nakhleh, M., (1992). “Why Some Students Don't Learn Chemistry", Journal of Chemical Education, 1992, 69(3) 191-196.

Novak, J. D.(2000). Meaningful learning: The essential factor for conceptual change in Limited or Inappropriate Propositional Hierarchies (LIPHs) leading to empowerment of learners, jdn2@gte.net, Cornell University. Retrieved 27 February, 2009.

O'Brien, R..(1998). An Overview of the Methodological Approach of Action Research. Faculty of Information Studies, University of Toronto. obrienr@fis.utoronto.ca

O” zmen, H. (2004). Some Student Misconceptions in Chemistry: A Literature Review of Chemical Bonding, Plenum Publishing Corporation.

Pheeney, P. (1998). Portfolio. Science Teacher, 65 (4) 36-39.

Posner, G. J., Strike, K. A., Hewson, P. W., and Gertzog, W. A. (1982). Accommodation of a scientific conception: Towards a theory of conceptual change. Science Education 66: 211-217. 
Priscilla, R. (2002). Qualitative Methods: A field guide for applied research in sexual and reproductive health. Family Health International: North Carolina. pp 28-29.

Strauss, S. (1981). Cognitive development in school and out. Cognition, 10, 295-300

Taber, K. S., and Watts, M. (1997). Constructivism and concept learning in chemistry: Perspectives from a case study. Researching Education 58: 10-20.

Taber, K. (2000). Chemistry lessons for universities?: A review of constructivist ideas. University Chemistry Education 4: 63-72.

Taber, K. S. (1998). Physics in Chemistry [Key concept: the chemical bond]). International Journal of Science Education 20(5) 597.

Taber, K. S. (2001). Constructing chemical concepts in the classroom?: Using research to inform the practice. Chemistry Education:_Research and Practice in Europe 2: 4351.

Tsaparlis, G. (1997). Atomic and molecular structure in chemical education: A critical analysis from various perspectives of science education. Journal of Chemical Education 74: 922-925.

Valanides, N. (2000). Primary student teachers' understanding of the particulate nature of matter and its transformations during dissolving. Chemistry Education: Research and Practice in Europe 1: 249-262.

Winter, R. (1989). Learning from experience: principles and practice in action research. London: Falmer Press: 36-68.

Yager, R. E. (1991). The Constructivist Learning Model. Science Teacher, 67 (1) 4-45.

Zoller, U. (1996). The Use of Examinations for Revealing and Distinguishing Between Students' Misconceptions, Misunderstandings and "No Conceptions" in College Chemistry, Research in Science Education, 26(3), 317-326 